\title{
Norovirus infections in children under 5 years of age hospitalized due to the acute viral gastroenteritis in northeastern Poland
}

\author{
E. Oldak • A. Sulik • D. Rozkiewicz • \\ N. Liwoch-Nienartowicz
}

Received: 7 January 2011 / Accepted: 8 June 2011 /Published online: 6 July 2011

(C) The Author(s) 2011. This article is published with open access at Springerlink.com

\begin{abstract}
The primary aim of this study was to evaluate the frequency and seasonality of norovirus infection in hospitalized Polish children under 5 years of age, and a secondary aim was to compare the clinical severity of norovirus and rotavirus disease. The prospective surveillance study was carried out from July 2009 through June 2010. Stool samples from 242 children hospitalized due to acute viral gastroenteritis were tested for rotavirus group A and adenovirus with commercial immunochromatographic test and for norovirus with EIA assay. Single norovirus infection was found in 35/242 (14.5\%) patients and in a further $5(2.1 \%)$ children as co-infection with rotavirus. Overall, norovirus was detected in $16.5 \%$ of stool specimens. Norovirus infections tended to peak from October to November and again from February to March. In autumn months and in February, the proportion of norovirus gastroenteritis cases was equal or even surpassed those of rotavirus origin. Both norovirus and rotavirus infections most commonly affected children between 12 and 23 months of age. The low-grade or no fever was significantly more common in children infected with norovirus (94.3\%) compared to rotavirus cases $(52.9 \%)$. Overall, norovirus gastroenteritis was less severe than rotavirus disease with regard to 20 -point severity scale $(p<0.05)$. Noroviruses have emerged as a relevant cause of acute gastroenteritis in Polish children. There is a great need for introducing routine norovirus testing of hospitalized children with gastroenteritis.
\end{abstract}

E. Oldak $(\bowtie) \cdot$ A. Sulik $\cdot$ D. Rozkiewicz $\cdot$

N. Liwoch-Nienartowicz

Department of Paediatric Infectious Diseases,

Medical University of Bialystok, University Children's Hospital,

Waszyngtona 17 ,

15-274 Bialystok, Poland

e-mail: elzbieta.oldak@umb.edu.pl

\section{Introduction}

Recently, norovirus gastroenteritis has been considered to be second to rotavirus gastroenteritis as the cause of children's hospital admissions worldwide [1-4]. After implementation of rotavirus vaccines into national immunization programs in the years 2006 and 2007, the role of norovirus gastroenteritis is expected to increase [5]. With regard to the overview of recent literature, norovirus gastroenteritis accounts for $6-48 \%$ of all acute gastroenteritis cases with an overall median of $14 \%$ [6]. Noroviruses are small $(27-35 \mathrm{~nm}$ in diameter), round-shaped, noncapsulated particles which are transmitted from person to person via the faecal-oral route, but droplet transmission after vomiting episodes can also occur. The small infective dose ( $<10$ viral particles), long-time shedding, multiple modes of transmission, wide genetic diversity of norovirus strains, and resistance to the environmental factors make them highly contagious $[1,7,8]$. Although norovirus gastroenteritis is commonly regarded as a mild, shortlasting intestinal disorder which resolves by itself, severe dehydration and subsequent hospitalization are common complications in very young and very old persons, especially in those immunocompromised and with underlying diseases.

Due to the non-specific clinical manifestation, the diagnosis of sporadic norovirus infection can be made by detection of viral nucleic acid using reverse transcriptionpolymerase chain reaction (RT-PCR) assays or by detection of viral antigens in faeces using the enzyme linked immunosorbent assays (ELISA) or the immunochromatographic (ICG) tests [9-11]. Recently, RT-PCR has been accepted as the "gold standard" in norovirus diagnostics, whereas ELISA or ICG testing are suitable, relatively inexpensive and rapid methods to determine norovirus 
gastroenteritis on a routine basis in order to undertake the necessary transmission-related precautions. In Poland, the solid epidemiological data on sporadic and outbreak norovirus infections are lacking due to the fact that noroviruses are not routinely searched for in diagnostic laboratories and, to date, there is no reference research laboratory to determine the currently circulating strains.

The primary aim of this study was to determine the frequency and seasonality of sporadic norovirus infections in Polish children under 5 years of age hospitalized due to the community-acquired, acute viral gastroenteritis in the 2009/2010 epidemic season and also to compare the clinical severity of rotavirus and norovirus disease. The epidemic season $2009 / 2010$ is the third one since chargeable rotavirus vaccines have been recommended to Polish infants. In 2009, the rotavirus vaccination coverage in northeastern Poland accounted for approximately 30\% of children up to 3 years of age.

\section{Material and methods}

\section{Setting}

The study was carried out in the 20-bed Department of Paediatric Infectious Diseases at University Children's Hospital in Bialystok, Poland. The department is located in northeastern Poland and provides inpatient care for children with acute gastroenteritis who reside in Bialystok city and Bialystok district. An estimated catchment population accounts for approximately 8,200 children aged $<5$ years, representing about $50 \%$ of all children aged $<5$ years in our region.

\section{Material}

All 373 children less than 5 years of age admitted to our department due to the community-acquired, acute viral gastroenteritis between July 2009 and June 2010 were invited to participate in the study project. The acute viral gastroenteritis was considered as abrupt onset of diarrhoea (three or more episodes of watery stool in a period of $24 \mathrm{~h}$ ) and/or vomiting with or without fever. Inclusion criteria were: age less than 5 years and informed consent obtained from parents or legal guardians. Patients with diarrhoea of over 7 days' duration, an antibiotic treatment before presentation, underlying diseases or confirmed bacterial diarrhoea were excluded. Overall, 242 children were enrolled in the study.

Methods

For each child, stool samples were collected within 36 hours of admission. Rotavirus group A and adenovirus were tested in fresh faecal specimens on a routine basis by means of commercial, ICG assay (VIKIA Rota-Adeno, Biomerieux). Then, the same stool samples for norovirus detection were frozen and stored in $<20^{\circ} \mathrm{C}$ for future simultaneous testing

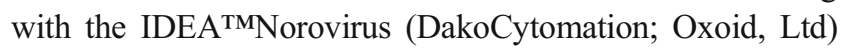
according to the manufacturer's instruction.

To assess severity of illness the clinical data (duration and frequency of diarrhoea and vomiting and the presence of fever and dehydration) were determined. The severity of gastrointestinal disease was estimated with the numerical scoring system of Ruuska and Vesikari [12]. Rotavirus immunization status was also recorded.

Statistical analysis was performed with Statistica StatSoft, version 9. The Mann-Whitney U-test was used to compare quantitative variables and chi-squared test for comparison of proportions. All tests were two-tailed and the difference was considered statistically significant when $p<0.05$.

The study was approved by the Research Ethical Committee of the Medical University in Bialystok.

\section{Results}

During the one-year surveillance period a total of 242 children (114 males) with acute viral gastroenteritis were enrolled. As we estimated, they accounted for approximately $3 \%$ of the catchment population. Nine out of $242(3.7 \%)$ children were vaccinated against rotavirus disease. Stool samples obtained from enrolled children were tested for enteric viruses. The causative agent of viral gastroenteritis was detected in $105 / 242(43.4 \%)$ cases. Single norovirus infection was found in $35 / 242(14.5 \%)$ patients, rotavirus in $51 / 242(21.1 \%)$ and adenovirus in $14 / 242(5.8 \%)$ patients. Dual viral-viral co-infection was confirmed in a further $5 / 242$ $(2.1 \%)$ cases. To assess the norovirus gastroenteritis burden in Polish children, relative prevalence of major viral agents norovirus, rotavirus group A and adenovirus was determined in positive-tested faecal specimens.

Rotavirus group A was the most prevalent single agent and was detected in $48.6 \%(51 / 105)$ of stool samples, including one stool sample coming from a vaccinated child. Norovirus was present in 33.3\% (35/105) and adenovirus in $13.3 \%(14 / 105)$ of the specimens. Dual norovirus and rotavirus infection was detected in $3.8 \%(4 / 105)$ of cases and dual norovirus and adenovirus infection in one patient (1\%). Overall, norovirus was detected in $16.5 \%(40 / 242)$ of the samples tested.

Although norovirus gastroenteritis cases were recorded throughout the year, they tended to peak in autumn months from September to November and again from January to March (Fig. 1). In autumn months and in February, the proportion of norovirus gastroenteritis cases was equal or even surpassed those of rotavirus origin. Among 35 
Fig. 1 Monthly distribution of norovirus (NV) and rotavirus (RV) cases (a), and proportions (b) in enrolled children. The black bars indicate norovirus cases; empty bars indicate rotavirus cases
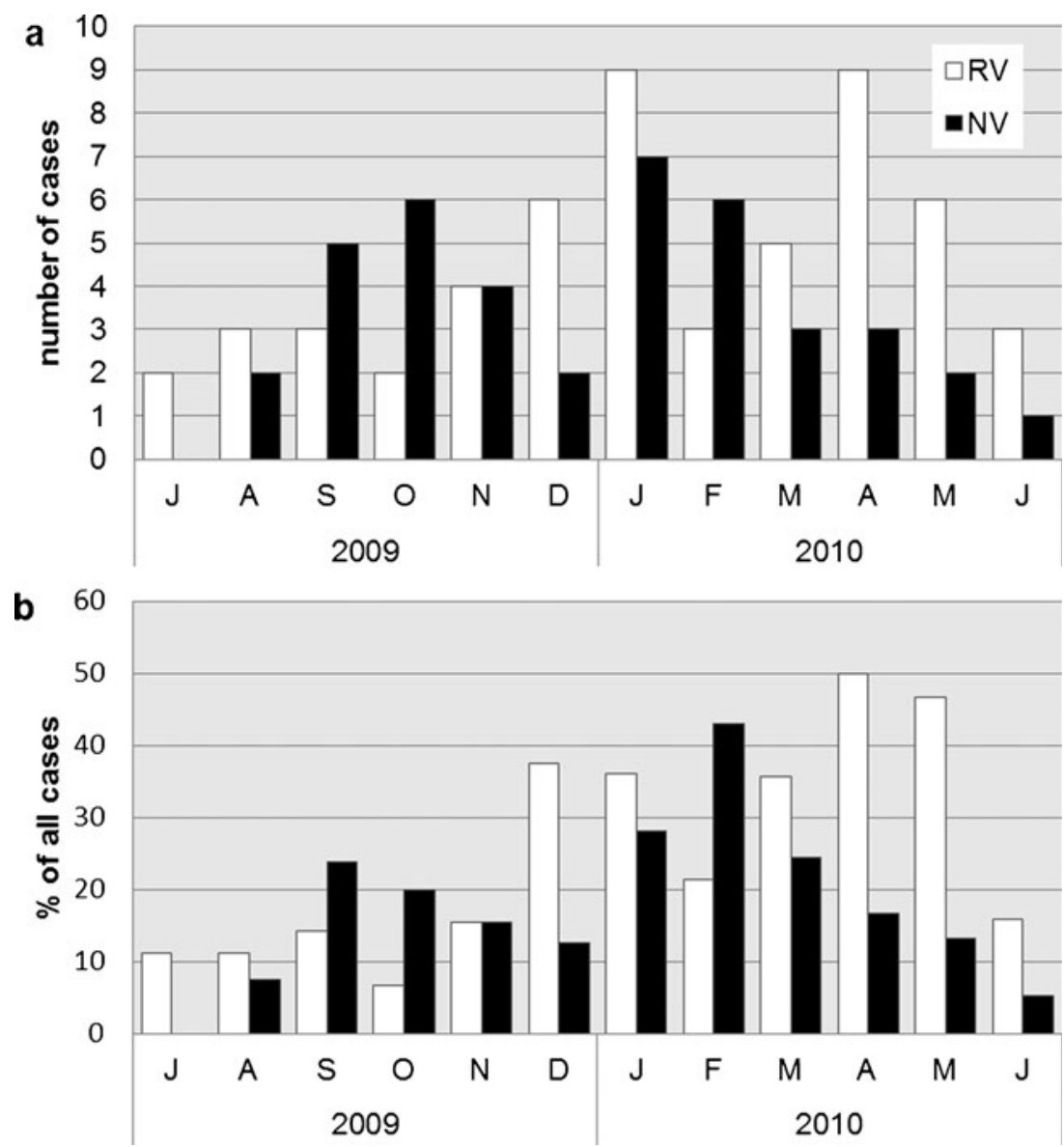

children diagnosed with sporadic norovirus disease, $80 \%$ (28/35) were hospitalized from October through March. The median age of children infected with norovirus and rotavirus was similar and accounted for 17 months (range 1-57) and 18 months (range 4-57), respectively. The ageadjusted distribution of norovirus gastroenteritis cases compared to rotavirus gastroenteritis cases is presented in Fig. 2. The majority of norovirus infections was recorded in children up to 2 years of age $(74 \%)$. Both norovirus and

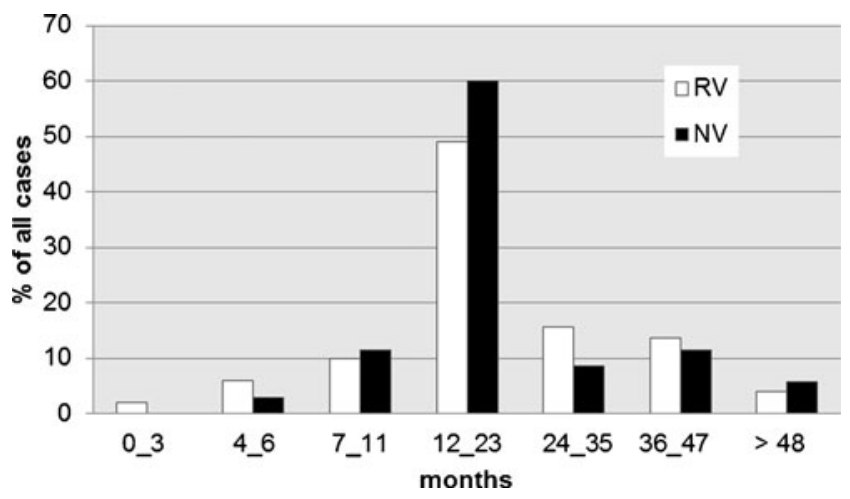

Fig. 2 Age-adjusted distribution of norovirus (NV; black bars) and rotavirus (RV; empty bars) infections in enrolled children rotavirus infections most commonly affected children between 12 and 23 months of age.

As we assessed, norovirus disease was similar to rotavirus disease with regard to frequency and duration of diarrhoea and vomiting (Table 1). The low-grade or no fever was significantly more common in children infected with norovirus $(94.3 \%)$ compared to rotavirus cases (52.9\%). Overall, norovirus gastroenteritis was a less severe disease than rotavirus disease with regard to the 20-point severity scale $(p<0.05)$.

\section{Discussion}

This study is the third one coming from our facility which deals with norovirus infections in Polish children [13, 14]. After searching the recent polish literature adhering to this topic, we found only one study based on data coming from a routine surveillance system on foodborne and waterborne norovirus outbreaks in Poland [15]. Recently, many reports have established the importance of noroviruses as a cause of outbreaks [16-18]. Community-acquired, sporadic cases of norovirus gastroenteritis have been known to a much less extent since individual cases are poorly diagnosed and 
Table 1 Clinical manifestation of norovirus (NV) and rotavirus (RV) infections according to 20-point severity score $[12]$
${ }^{a}$ All children were hospitalized and therefore received an extra 2 points

Figures in bold highlight the highest value

\begin{tabular}{|c|c|c|c|c|}
\hline Clinical symptoms & Score & $\mathrm{NV}, n=35 ;(\%)$ & $\mathrm{RV}, n=51 ;(\%)$ & $p$ value \\
\hline \multicolumn{5}{|c|}{ Duration of diarrhea (days) } \\
\hline 0 & 0 & 0 & 0 & \multirow[t]{4}{*}{0.17} \\
\hline $1-4$ & 1 & $30(\mathbf{8 5 . 7})$ & $35(68.6)$ & \\
\hline 5 & 2 & $1(2.9)$ & $5(9.8)$ & \\
\hline$\geq 6$ & 3 & $4(11.4)$ & $11(21.6)$ & \\
\hline \multicolumn{5}{|c|}{ Diarrhea episodes $/ 24 \mathrm{~h}$} \\
\hline 0 & 0 & 0 & 0 & \multirow[t]{4}{*}{0.09} \\
\hline 1 & 1 & $16(45.7)$ & $12(23.5)$ & \\
\hline 2 & 2 & $10(28.6)$ & $22(43.1)$ & \\
\hline$\geq 3$ & 3 & $9(25.7)$ & $17(33.4)$ & \\
\hline \multicolumn{5}{|c|}{ Duration of vomiting (days) } \\
\hline No vomiting & 0 & $1(2.8)$ & $5(9.8)$ & \multirow[t]{4}{*}{0.13} \\
\hline 1 & 1 & $15(42.9)$ & $19(\mathbf{3 7 . 3})$ & \\
\hline 2 & 2 & $12(34.3)$ & $9(17.6)$ & \\
\hline$\geq 3$ & 3 & $7(20.0)$ & $18(35.3)$ & \\
\hline \multicolumn{5}{|c|}{ Vomiting episodes $/ 24 \mathrm{~h}$} \\
\hline No vomiting & 0 & $1(2.8)$ & $5(9.8)$ & \multirow[t]{4}{*}{0.15} \\
\hline 1 & 1 & $6(17.1)$ & $4(7.8)$ & \\
\hline $2-4$ & 2 & 15 (42.9) & $30(\mathbf{5 8 . 8})$ & \\
\hline$\geq 5$ & 3 & $13(37.1)$ & $12(23.6)$ & \\
\hline \multicolumn{5}{|l|}{ Fever $\left({ }^{\circ} \mathrm{C}\right)$} \\
\hline$<37.0$ & 0 & $25(71.4)$ & $15(\mathbf{2 9 . 4 )}$ & \multirow[t]{4}{*}{0.002} \\
\hline $37.1-38.4$ & 1 & $8(22.9)$ & $12(23.5)$ & \\
\hline $38.5-38.9$ & 2 & $2(5.7)$ & $13(25.5)$ & \\
\hline$\geq 39.0$ & 3 & 0 & $11(21.6)$ & \\
\hline \multicolumn{5}{|l|}{ Dehydration } \\
\hline None & 0 & 0 & 0 & \multirow[t]{3}{*}{0.40} \\
\hline $1-5 \%$ & 2 & $35(\mathbf{1 0 0})$ & $50(\mathbf{9 8 . 0})$ & \\
\hline$\geq 6 \%$ & 3 & 0 & $1(2.0)$ & \\
\hline \multicolumn{5}{|l|}{ Severity score ${ }^{a}$} \\
\hline Mild & $0-7$ & 0 & $1(2.0)$ & \multirow[t]{3}{*}{0.01} \\
\hline Moderate & $8-13$ & $30(\mathbf{8 5 . 7})$ & $28(\mathbf{5 4 . 9})$ & \\
\hline Severe & $14-20$ & $5(14.3)$ & $22(43.1)$ & \\
\hline
\end{tabular}

reported. In Poland like in many other countries, noroviruses are not covered by routine analysis of stool samples from patients with gastroenteritis, and therefore the problem of norovirus infections has been underappreciated. However, as we have documented in the present study, the incidence of single norovirus gastroenteritis in Polish children under 5 years of age is relatively high and accounts for $14.5 \%$ of all hospitalized acute gastroenteritis cases and for $33.3 \%$ of those of specified aetiology. The norovirus positivity rate in hospitalized Polish children increased by $3 \%$ compared to the results of our pilot study performed in 2005 [13]. It is likely that the observed increase in relative frequency of norovirus gastroenteritis cases is due to implementing a rotavirus vaccination in Polish infants since the 2006-2007 epidemic season. Patel et al. [4], reviewing the results of recent studies in which molecular methods were applied for detection of enteric viruses, showed that noroviruses accounted for approximately $12 \%$ (range $4.4-30.7 \%$ ) of severe gastroenteritis cases among children $<5$ years of age worldwide. In turn, Koopman [6], searching the recent literature results for prevalence of norovirus in hospitalized children with acute gastroenteritis across the world, calculated the median value at the level of $14 \%$. To our knowledge, the lowest prevalence of sporadic norovirus gastroenteritis in European children was recorded in Hungary [19] at $6.5 \%$, whereas the highest were in Italy [20] at 39.2\% and in Finland [5] at 29\%. Observed discrepancies in frequency of norovirus disease need to be interpreted with caution. Many factors such as study design and duration, age of patients, epidemic season or methods applied may influence the final results. The IDEA enzyme immunoassay applied in this study is considered as highly specific for some noroviruses, but generally not sensitive enough to detect a wide range of noroviruses [9, 10]. Assuming that 
the sensitivity of the IDEA norovirus assay for detecting norovirus in samples collected in sporadic cases of gastroenteritis ranges from 44.6 to $75.9 \%$ [9], the real incidence of norovirus gastroenteritis in the present study is expected to be higher. Our results confirm the relevance of norovirus second to rotavirus as the cause of severe gastroenteritis in young Polish children. A limitation of the recent study is the lack of the possibility to determine the molecular characteristics of circulating norovirus strains.

In the present study, norovirus gastroenteritis cases were detected all year round, except July. We observed two peak waves, one in September-October and the second one from January to March. The same seasonality pattern was observed in our previous study [13]. Norovirus infections preceded the epidemic increase of rotavirus cases by two months. Similar regularity concerning winter predominance of norovirus infections was observed by many in previous studies [5, 20-23].

The overall severity score was significantly lower for norovirus infection compared to rotavirus gastroenteritis cases. This is probably due to a lower frequency of highgrade fever and evacuations in norovirus infected children. Similar results were found by Junquera et al. [3] in Spain and by Narkeviciute and Tamusauskaite [24] in Lithuania.

In conclusion, in light of recent findings, noroviruses have emerged as a relevant cause of acute, communityacquired gastroenteritis in Polish children. There is a great need for introducing the routine norovirus testing in hospitalized patients with gastroenteritis and to find at least one National Virus Reference Laboratory to recognize the real burden as well as molecular epidemiology of viral intestinal infections in the Polish childhood population.

Acknowledgments The study was financially supported by the Medical University of Bialystok internal grant number 3-48695 L.

The authors declare that they have no conflict of interest.

Open Access This article is distributed under the terms of the Creative Commons Attribution Noncommercial License which permits any noncommercial use, distribution, and reproduction in any medium, provided the original author(s) and source are credited.

\section{References}

1. Koopmans M (2009) Noroviruses in healthcare settings: a challenging problem. J Hosp Infect 73:331-337

2. Patel MM, Widdowson MA, Glass RI, Akazawa K, Winjé J, Parashar UD (2008) Systematic literature review of role of noroviruses in sporadic gastroenteritis. Emerg Infect Dis 16:1224-1231

3. Junquera GC, Sainz de Baranda C, Mialdea GO, Serrano EB, Sanchez-Fauquirez A (2009) Prevalence and clinical characteristics of norovirus gastroenteritis in hospitalized children in Spain. Pediatr Infect Dis J 28:604-607
4. Patel M, Hall AJ, Vinjé J, Parashar UD (2009) Noroviruses: a comprehensive review. J Clin Virol 44:1-8

5. Zeng SQ, Halkosalo A, Salminen M, Szakal ED, Karvonen A, Vesikari T (2010) Norovirus gastroenteritis in young children receiving rotavirus vaccine. Scand $J$ Infect Dis 42:540-544

6. Koopman M (2008) Progress in understanding norovirus epidemiology. Curr Opin Infect Dis 21:544-552

7. Barker J, Vipond IB, Bloomfield SF (2004) Effects of cleaning and disinfection in reducing the spread of norovirus contamination via environmental surfaces. J Hosp Infect 58:42-49

8. Teunis PF, Moe CL, Liu P, Miller SE, Lindesmith L, Barick RS et al (2008) Norwalk virus: how infectious is it? J Med Virol 80:1468-1476

9. Gray JJ, Kohli E, Ruggeri FM, Vennema H, Sánchez-Fauquier A, Schreier E et al (2007) European multicenter evaluation of commercial enzyme immunoassays for detecting norovirus antigen in fecal samples. Clin Vaccine Immunol 14:13491355

10. Kirby A, Gurgel RQ, Dove W, Vieira SCF, Cunliffe NA, Cuevas LE (2010) An evaluation of the RIDASREEN and IDEA enzyme immunoassays and the RIDAQUICK immuno-chromatographic test for the detection of norovirus in faecal specimens. J Clin Virol. 49(4):254-257. doi:10.1016/jcv.2010.08.004

11. Bruins MJ, Wolfhagen MJHM, Schirm J, Ruijs GJHM (2010) Evaluation of a rapid imunochromatographic test for the detection of norovirus in stool samples. Eur J Clin Microbiol Infect Dis 29:741-743

12. Ruuska T, Vesicari T (1990) Rotavirus disease in Finnish children: use of numerical scores for clinical severity of diarrheal episodes. Scand J Infect Dis 22(3):259-267

13. Sulik A, Pogorzelska E, Wojtkowska M, Rozkiewicz D, Oldak E (2007) Norovirus infections in children from northeastern Poland, hospitalized due to the acute diarrhea. Przegl Epidemiol 61:477482 (in Polish)

14. Oldak E, Sulik A, Rozkiewicz D, Liwoch-Nienartowicz N, Zawadzka E (2009) Norovirus and rotavirus - two major causative agents of sporadic viral gastroenteritis in hospitalized Polish children. Adv Med Sci 54:183-186

15. Napiórkowska A, Sadkowska-Todys M (2010) Epidemiological situation of human norovirus infections in Poland during 2004 2008. Przegl Epidemiol 64:27-33 (in Polish)

16. Siebenga JJ, Vennema H, Koopmans MPG (2007) Gastroenteritis caused by Norovirus GGII.4, the Netherlands, 1994-2005. Emerg Infect Dis 13:144-146

17. Manula L, Roivainen M, Keränen M, Mäkalä S, Söderberg K, Summa M et al (2009) Detection of human norovirus from frozen raspberries in a cluster of gastroenteritis outbreaks. Euro Surveill 14(49):19435. http://www.eurosurveillance.org/ViewArticle.aspx? ArticleId=19435. Accessed 24 November 2009

18. Westrell T, Dusch V, Ethelberg S, Harris J, Hjertqvist M, Jourdan-da Silva N, Koller A, Lenglet A, Lisby M, Vold L (2010) Norovirus outbreaks linked to oyster consumption in the United Kingdom, Norway, France, Sweden and Denmark, 2010. Euro Surveill 15 (12):19524. http://www.eurosurveillance.org/VieArticle.aspx?/ Articleld $=19524$. Accessed 25 March 2010

19. Jacab F, Nemeth V, Oldal M, Varga L, Nyul Z, Mitchell DK, Matson DO, Szucs G (2010) Epidemiological and clinical characterization of norovirus infections among hospitalized children in Baranya County, Hungary. J ClinVirol 49:75-76

20. Colomba C, Saporito L, Giammanco GM, De Grazia S, Ramirez S, Arista S, Titone L (2007) Norovirus and gastroenteritis in hospitalized children, Italy. Emerg Infect Dis 13:13891391

21. Beersma MFC, Schutten M, Vennema H, Hartwig NG, Mes THM, Osterhaus ADME, van Doornum GJJ, Koopmans M (2009) 
Norovirus in a Dutch tertiary care hospital (2002-2007): frequent nosocomial transmission and dominance of GIIb strains in young children. J Hosp Infect 71:199-205

22. Fretz R, Hermann L, Christen A, Svoboda P, Dubuis O, Viollier EH, Tanner M, Baumgartner A (2005) Frequency of norovirus in stool samples from patients with gastrointestinal symptoms in Switzerland. Eur J Clin Microbiol Infect Dis $24: 214-216$
23. Nakagomi T, Correia JB, Nakagomi O, Montenegro FMU, Cuevas LE, Cunliffe NA, Hart CA (2008) Norovirus infection among children with acute gastroenteritis in Recife, Brazil: disease severity is comparable to rotavirus gastroenteritis. Arch Virol 153:957-960

24. Narkeviciute I, Tamasauskaite I (2008) Peculiarities of norovirus and rotavirus infections in hospitalized young children. J Pediatr Gastroenterol Nutr 46:289-292 